\title{
Correction to: Neuropsychological and internalizing problems in acute central nervous system infections: a 1 year follow-up
}

Elena Bozzola ${ }^{1 *}$, Paola Bergonzini ${ }^{1}$, Mauro Bozzola ${ }^{2}$, Alberto Eugenio Tozzi ${ }^{3}$, Marco Masci ${ }^{1}$, Chiara Rossetti ${ }^{1}$, Emanuela Carloni ${ }^{3}$ and Alberto Villani ${ }^{1}$

\section{Correction}

The original article [1] contained an error mistakenly carried forward by the Production department handling this article whereby all authors' names were incorrectly inverted.

The original article has now been corrected to reflect the correct names of all authors.

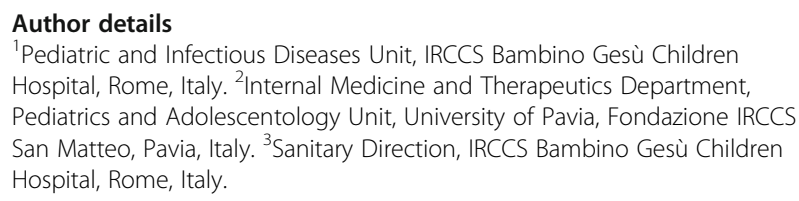

\section{Reference}

1. Bozzola E, et al. Neuropsychological and internalizing problems in acute central nervous system infections: a 1 year follow-up. Ital J Pediatr. 2017;43:96.

\footnotetext{
*Correspondence: elena.bozzola@opbg.net

${ }^{1}$ Pediatric and Infectious Diseases Unit, IRCCS Bambino Gesù Children

Hospital, Rome, Italy

Full list of author information is available at the end of the article
} 